\title{
Patterns of growth and smolting in autumn migrants from a Scottish population of Atlantic salmon, Salmo salar $\mathbf{L}$.
}

\author{
F. A. Huntingford, J. E. Thorpe*, C. Garcia de Leaniz $\dagger$ and D. W. Hay* \\ Zoology Department, University of Glasgow, Glasgow G12 $8 Q Q$ and \\ *SOAFD Freshwater Fisheries Laboratory, Pitlochry PHI6 5LB, U.K.
}

\begin{abstract}
In late November 1990 saimon parr, Salmo salar L., from the Girnock Burn in northern Scotland were either caught on their feeding territories $(n=25)$ or trapped during downstream migration $(n=18)$. They were then housed in a laboratory rearing tank and their food intake and growth rates were tracked, until their smolting status was ascertained in the following May. Female fish were predominant in both groups; although the range of ages was the same, the total age of migrants was $2+$ while that of residents was $1+$. In November, compared to resident fish of the same year class, migrants were larger, heavier and in better condition. Although growth rates dropped during the winter in both groups before increasing in spring, migrants ate more and consistently grew faster than residents. In seawater tolerance tests conducted in May, more residents than migrants failed to adapt. These results confirm the suggestion that autumn migrants smolt in the following spring and suggest that they represent the faster-growing component of their cohort.
\end{abstract}

Key words: Salmo salar; growth; smolting; autumn migration.

\section{INTRODUCTION}

In small streams in Northern Scotland a proportion of juvenile Atlantic salmon, Salmo salar L., migrate downstream in autumn (Pyefinch \& Mills, 1963; Mills, 1989). For example, in the Girnock Burn, Aberdeenshire, Scotland, one wave of emigration (involving fish that still had parr colouration) occurred between midSeptember and mid-February, peaking in late November, and a second occurred between early March and June, peaking in April (Buck \& Hay, 1984). In both cases, it seems likely that most emigration occurred at night (Thorpe et al., 1988). While a great deal is known about the spring migration, which corresponds to the widely occurring and well-documented smolt run, both the immediate causes and the consequences of the autumn migration are poorly understood.

Egglishaw \& Shackley (1973) recorded the disappearance of juvenile salmon $>9 \mathrm{~cm}$ in fork length from the Fender Burn, Perthshire, Scotland, between September and December; these fish were presumed to have emigrated rather than died. Morrison (1989) recorded a slight decrease in mean length of $1+$ juvenile salmon in the Fiddich Burn at three sites between October and April in 1977-1979 and, on a neighbouring stream, a decrease in the variance of length between August and February. Although the author did not explain these decreases, their existence is consistent with emigration of fishes whose mean lengths were above average.

Analyses of scales of returning adult salmon that were tagged as juveniles on emigration from the Girnock Burn showed that autumn migrant parr smolted and entered the sea the following spring, suggesting that the autumn migrants represent

†Xunta de Galicia, Conselleria de Agricultura, Dir. Gral. Montes y Medio Ambiente Natural, C.I.F. Lourizán, Pontevedra 38030, Spain. 
the start of the smolt run (Buck \& Hay, 1984), as previously recorded by Calderwood (1906) and Meister (1962). Migrants ranged in age from $1+$ to $4+$, with the majority being aged $2+$ in 9 out of 10 years (Buck \& Hay, 1984).

High rates of emigration in autumn are associated with high discharge rates (Youngson et al., 1983), but it is not clear why only a proportion of the fish respond to faster currents by moving out of the system. It has been suggested that autumn migrants are subordinate fish driven out of the system by their more dominant companions [e.g. in chinook salmon, Oncorhynchus tschawytscha Walbaum (Bjornn, 1971), and in coho salmon, O. kisutch Walbaum (Mason, 1976)]. However, in the Girnock Burn the number of autumn migrants is not density dependent (Youngson et al., 1983), as might be expected if this were the case.

Therefore, although the autumn and spring migrants must be different, the nature of this difference is obscure. The aim of the present study was to clarify the status of autumn migrants by: (1) comparing age, sex, size and body condition in autumn migrants and residents caught at the same time in the same river; (2) tracking subsequent patterns of growth, food intake and smolting in the two categories of fish kept under identical conditions.

\section{MATERIALS AND METHODS}

\section{CAPTURE AND MAINTENANCE OF FISH}

Autumn migrants and residents were captured in the Girnock Burn, which is fitted with a modified Wolf trap (Wolf, 1950) for continuous capture of all fish moving downstream (see Buck \& Hay, 1984). On 28 November 1990, 25 immature parr were collected on their feeding territories by electrofishing. These fish (residents) were batch-marked on the righthand side of the ventral surface with a single Alcian blue dye-spot in front of the pelvic fin using a Panjet inoculator. On the same date the 18 migrant parr caught in the Wolf trap up to that date were batch-marked, also by Panjet inoculation, but behind the right pelvic fin. The fish were transported to the SOAFD Freshwater Fisheries Laboratory, Pitlochry, Perthshire on 19 December, where they were marked individually with a combination of Alcian blue dye-spots on left side. They were housed outside in a 2-m diameter radial flow tank at ambient temperature and day length, and fed to excess on EWOS salmon feed.

\section{MONITORING BODY SIZE AND CONDITION}

The fish were measured to the nearest $1 \mathrm{~mm}$ fork length $(L)$, and weighed to the nearest $0.1 \mathrm{~g}(W)$ on first transfer to the holding tank, and on six subsequent occasions up to 17 May 1991 (see Fig. 1). On these occasions they were re-marked if necessary. On 23 April, additional measurements of opercular height $(H O)$, opercular width $(W O)$ and adipose fin length $(A P)$ were taken, and condition factor $(K)$ calculated for an assessment of total lipid levels, using a non-destructive method devised by Simpson et al. (1992). $\left[K=W / L^{b}\right.$, where $b$ is the slope of the regression of $\log _{10} W$ on $\log _{10} L$ (Bolger \& Connolly, 1989).] Percentage fat was then calculated from the equation:

$$
\% \text { fat }=-46 \cdot 5-0.707 \mathrm{~W}+0.368 \mathrm{~L}+735 \mathrm{~K}+199 \mathrm{HO}+103 \mathrm{WO}-21 \cdot 4 \mathrm{AP}
$$

which predicts total body lipid with an accuracy of $94 \%$ (Simpson et al., 1992). Once the fish were killed (see below) the presence or absence of mesenteric fat was recorded (see Rowe et al., 1991).

\section{MONITORING FOOD INTAKE}

On 14 March 1991, for a period of 1-2 h, the fish were fed pellets containing radio-opaque markers (Talbot \& Higgins, 1983), then anaesthetized, X-rayed and the number of pellets eaten during this time assessed. 

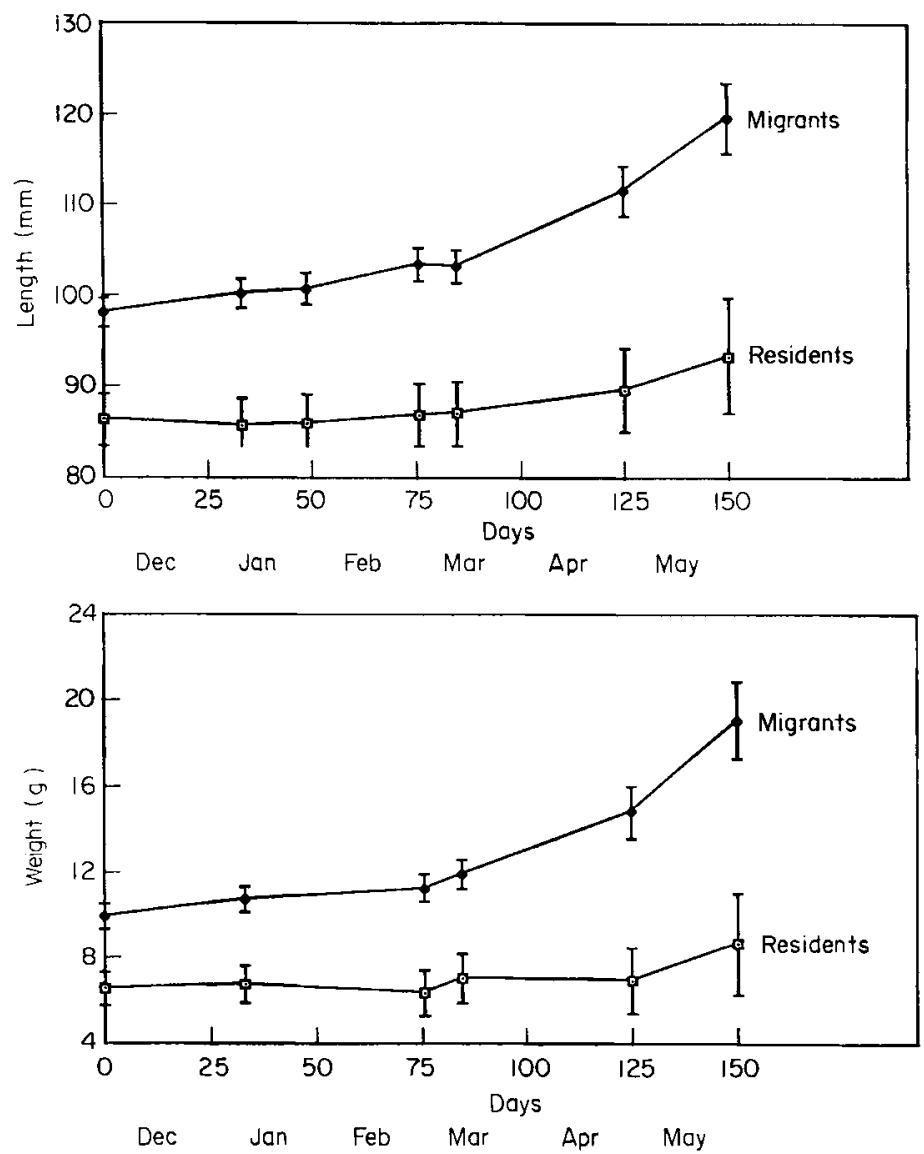

FIG. 1. Mean ( \pm s.E.) length (mm) and weight (g) of Atlantic salmon captured as migrants and as residents, on successive sampling dates. Sampling dates were 19.12.90, 21.1.91, 6.2.91, 5.3.91, 14.3.91, 23.4.91, 17.5.91. There was a significant regression between date and both length and weight for both categories of fish. However, the slopes of the regression lines for residents and migrants differed for length $\left(F_{1.231}=6.91, P<0.01\right)$ and for weight $\left(F_{1,200}=11 \cdot 10, P<0.001\right)$.

\section{SEAWATER TOLERANCE TESTS}

After measurement on 23 April the fish were transferred to Glasgow University Zoology Department, held for a week at $10^{\circ} \mathrm{C}$ to recover from transit, and then tested for seawater tolerance. At 08.00 hours they were transferred to $40 \mathrm{ppt}$ artificial sea water (Komourdjian et al., 1976) at $10^{\circ} \mathrm{C}$. Subsequently they were checked at hourly intervals, and removed when they showed signs of being unable to maintain balance. The aim of this procedure was to provide a non-lethal test of seawater tolerance. Unfortunately, after $14 \mathrm{~h}$ the compressed air supply failed, resulting in death of all the remaining fish. Therefore we have classified the fish into one of three categories, namely those that had been removed within $7 \mathrm{~h}$, those removed within $14 \mathrm{~h}$, and those still swimming normally at $14 \mathrm{~h}$. Since the sample sizes were too small to allow any effects of body size on seawater tolerance to be removed statistically, smolting status was also assessed by recording the presence of the silver smolt coloration, as opposed to the parr marks typical of non-smolting fish.

\section{AGING AND SEXING}

After the seawater tolerance tests, all the remaining fish were killed and a scale sample taken from the upper flank anterior to the dorsal fin. Acetate impressions of these were used to assign fish to year-classes. The fish were then dissected and sexed. 
TABLE I. Age structure of salmon parr captured as migrants or residents in December 1990; the number of fish in each age class

\begin{tabular}{lrrrr}
\hline & \multicolumn{4}{c}{ Year-class } \\
\cline { 2 - 5 } & 1987 & 1988 & 1989 & 1990 \\
\hline Migrants & 2 & 12 & 4 & 0 \\
Residents & 2 & 5 & 15 & 3 \\
\hline
\end{tabular}

\section{RESULTS}

\section{INITIAL STATUS OF RESIDENTS AND MIGRANTS}

Seventy-nine per cent of migrants and $67 \%$ of residents were female $\left(\chi^{2}=4.56\right.$, $P<0.05$ and $1.74 \mathrm{Ns}$, respectively). The age distribution of migrants was significantly different from that of residents (Table I; $\chi^{2}=9.14 ; P<0.01$ ), with most migrants belonging to year-classes 1988 and 1989 (i.e. $1+$ and 2+) and most residents to year-class 1989 .

When first captured, migrants were larger and heavier than residents, both when comparing the whole sample (Fig. 1), and when comparing within age-classes for 1988 and 1989 (Fig. 2), the only years for which sample sizes were sufficient for statistical comparison (Table II). Somatic condition factor was also significantly higher in migrants than in residents (Fig. 3), in the whole sample and in the 1988 but not the 1989 cohort.

\section{SUBSEQUENT GROWTH AND BODY CONDITION}

Both length [Fig. 1(a)] and weight [Fig. 1(b)] remained higher in migrants than in residents throughout the study period. Growth rates were low during winter (Fig. 4), then increased in spring for both categories of fish, but were always significantly higher among migrants $\left(F_{1,25}=9 \cdot 2, P<0 \cdot 01\right)$ especially those of the 1988 cohort (Fig. 2). As a consequence of their higher growth rates, the size advantage of migrants became increasingly marked as the study progressed. This difference in growth rates appeared to be the result of a difference in food intake, because when screened in March, $50 \%$ of migrants but only $13 \%$ residents had food in their stomachs $\left(\chi^{2}=4.55 ; P<0.05\right)$.

Condition factor varied rather little with time (Fig. 3) but was consistently higher in migrants $\left(F_{1,196}=4.58, P<0.05\right)$. The fact that migrants were in better condition than residents was confirmed by their higher body lipid levels in April (Fig. 5; mean levels $4.41 \%$ and $3.33 \%$ respectively; $t=3.07, P<0.01$ ). Also, in May, more migrants than residents had visible visceral fat reserves $(50 \%$ versus $\left.13 \% ; \chi^{2}=4.55, P<0.05\right)$.

\section{SEAWATER TOLERANCE TESTS}

The majority of migrants maintained equilibrium for more than $14 \mathrm{~h}$ (Table III), whereas the majority of residents had lost equilibrium within $7 \mathrm{~h}\left(\chi^{2}=9 \cdot 72\right.$, d.f. $=1$, $P<0.01)$. The migrants that lost equilibrium were not necessarily of the 1989 cohort (and so smaller), and the residents that maintained equilibrium were not 

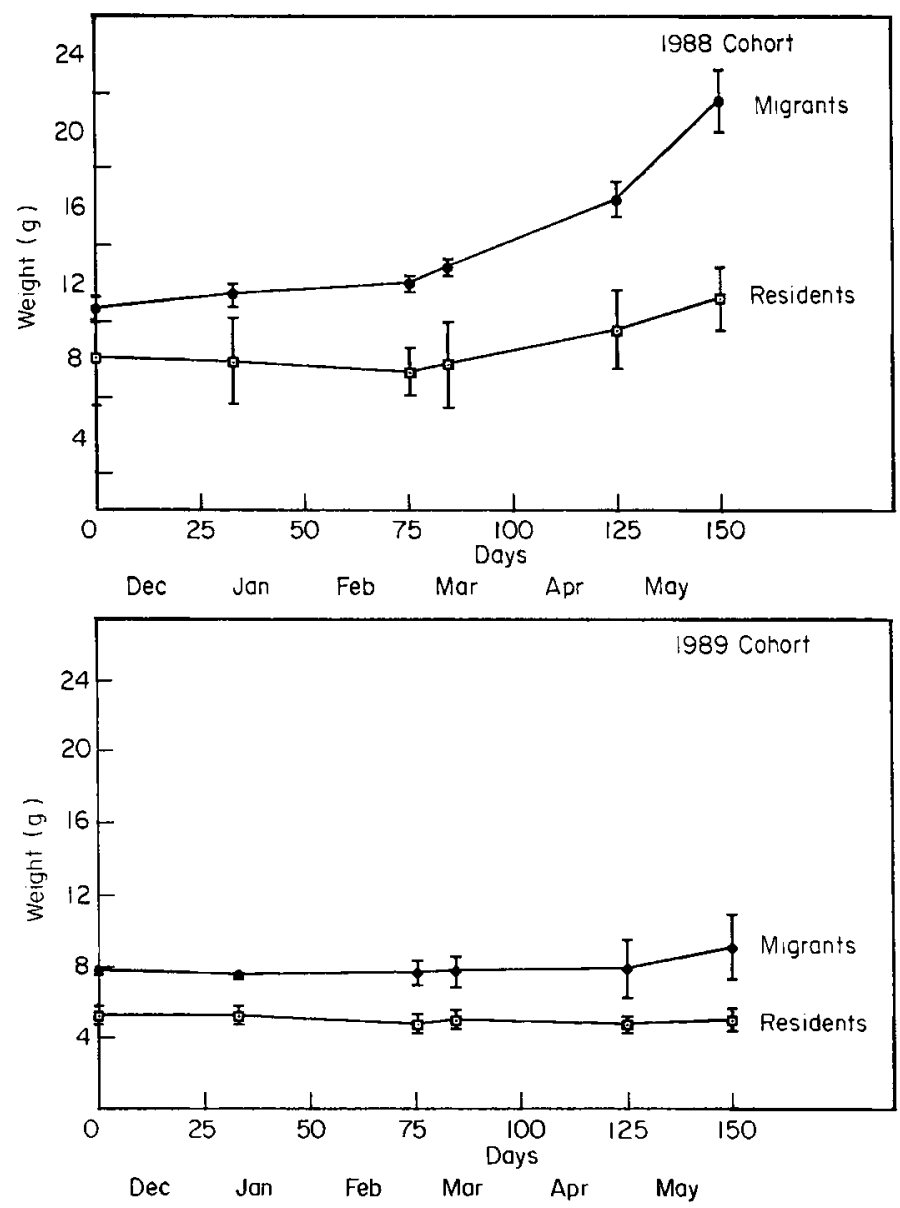

FiG. 2. Mean ( \pm S.E.) weight (g) of migrants and residents fish of the 1988 and 1989 cohorts on successive sampling dates. 1988: The slopes of the regression of weight on date are significantly different for residents and migrants $\left(F_{1,68}=7 \cdot 51, P<0 \cdot 01\right)$. 1989: Weight does not increase with date in either group, but migrants are consistently heavier than residents $\left(F_{1.65}=44.47, P<0.0001\right)$.

necessarily of the 1988 cohort (and so larger). Thus, the migrants in autumn 1990 were significantly more capable than were the residents of adjusting to sea water the following May, and so would probably have entered the sea at this time. In support of this, $87 \%$ of migrants but only $18 \%$ of residents showed silver colouration at this time $\left(\chi^{2}=4.57\right.$, d.f. $\left.=1, P<0.05\right)$.

\section{DISCUSSION}

This study has shown that most of the Atlantic salmon parr that migrated out of the Girnock Burn in the autumn were older than those remaining in the system. At the time that they left the burn, migrants were longer, heavier and in better condition than residents. These differences were observed within both the 1988 and 1989 year-classes, although as a result of the skewed age distribution in residents and migrants and subsequent small sample sizes, in some cases they were only marginally significant. This result confirms the observation of Youngson et al. (1983), that migrants were larger than residents, and raises the possibility that 
TABLE II. Sizes at capture of migrant and resident salmon parr in December 1990

\begin{tabular}{|c|c|c|c|c|c|c|}
\hline & Statistic & Year & Migrants & Residents & Test & $\begin{array}{c}\text { Difference } \\
P\end{array}$ \\
\hline \multirow[t]{3}{*}{$\begin{array}{l}\text { Length } \\
(\mathrm{mm})\end{array}$} & Median & 1988 & 100 & 92 & Mann-Whitney & $<0.10$ \\
\hline & Median & 1989 & 93 & 82 & Mann-Whitney & $<0.05$ \\
\hline & Mean & $1987-90$ & $98 \cdot 11$ & $86 \cdot 33$ & Student's $t$ & $<0.01$ \\
\hline \multirow[t]{3}{*}{ Weight $(\mathrm{g})$} & Median & 1988 & $10 \cdot 89$ & $7 \cdot 25$ & Mann-Whitney & $<0 \cdot 10$ \\
\hline & Median & 1989 & 7.67 & $5 \cdot 18$ & Mann-Whitney & $<0.05$ \\
\hline & Mean & $1987-90$ & $9 \cdot 96$ & $6 \cdot 54$ & Student's $t$ & $<0.01$ \\
\hline \multirow{3}{*}{$\begin{array}{l}\text { Condition } \\
\text { factor }\end{array}$} & Mean & 1988 & 1.04 & 0.95 & Student's $t$ & $<0.01$ \\
\hline & Mean & 1989 & 0.95 & 0.91 & Student's $t$ & N.S. \\
\hline & Mean & $1987-90$ & 1.06 & 0.96 & Student's $t$ & $<0.01$ \\
\hline
\end{tabular}

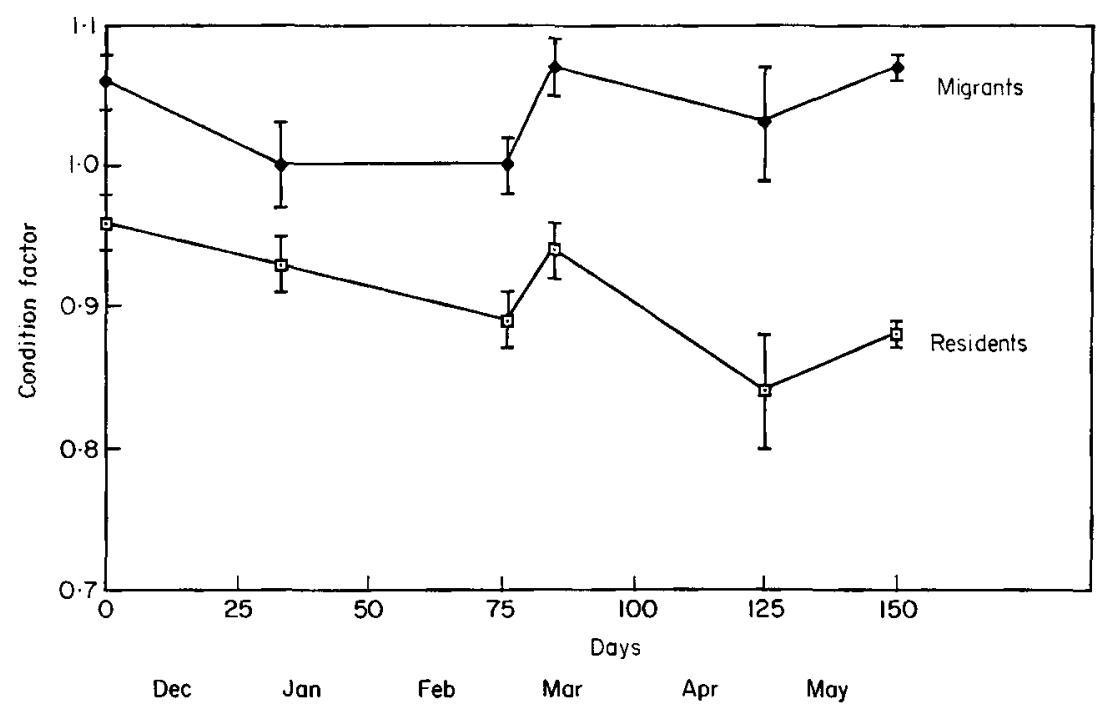

FiG. 3. Mean ( \pm s.E.) somatic condition factor (see text) for resident and migrant salmon on successive sampling dates.

within a year-class the fish that migrate in autumn may be equivalent to those that in intensive husbandry systems maintain fast growth during autumn and form the upper modal group of the size distribution. These fast-growing fish have higher somatic condition factors than their lower modal group siblings. This interpretation is strengthened by the fact that, like fish in the upper modal group, most autumn migrants smolt in the following spring (Thorpe et al., 1980).

If it is the larger and so presumably the more successful members of the population that migrate downstream in autumn, this emigration is unlikely to be the consequence of competitive expulsion of subordinate individuals from preferred territories. It is more probable that the emigrants leave because their immediate food needs are not being satisfied (Taylor \& Taylor, 1977), whereas the residents remain because their demands are less. This interpretation gains support from the 


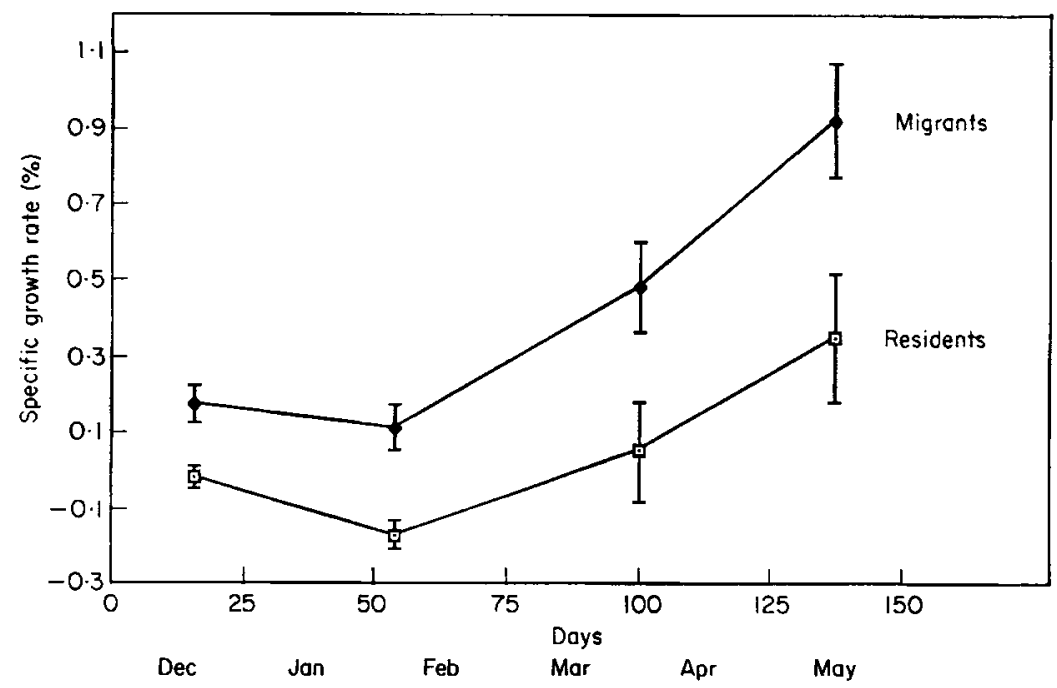

FIG. 4. Mean ( \pm S.E.) daily specific growth rates by weight for resident and migrant salmon on successive sampling dates.

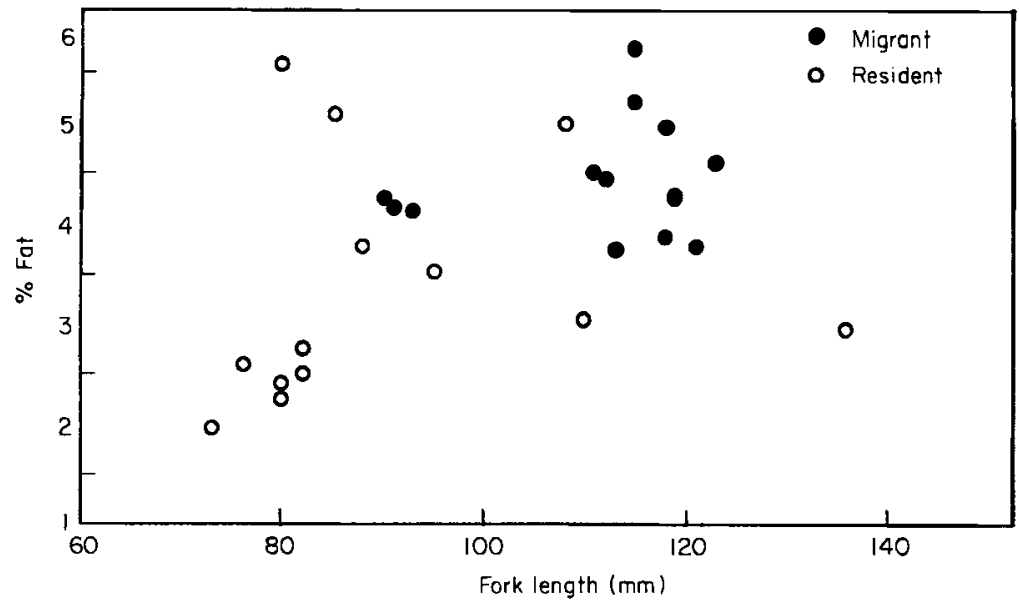

Fig. 5. Percentage fat in relation to length $(\mathrm{mm})$ in resident $(O)$ and migrant $(\bullet)$ salmon on 23 April 1991.

fact that, after transfer to the tanks, the migrants continued to feed and grow, whereas the residents fed and grew little.

The lower food intake and growth rates of the residents in the holding tanks might be the result of an inherent difference between these fish and their migrant compatriots, again perhaps analogous to the anorectic slow-growing state of lower modal group fish in intensive husbandry systems (Thorpe, 1977; Thorpe et al., 1980; Metcalfe et al., 1986, 1988; Metcalfe \& Thorpe, 1992). On the other hand it might reflect failure to compete for food with their larger migrant companions. The fish had ample space in the holding tank and food was provided in excess, but the possibility remains that the residents suffered a loss of appetite or reduced access to food contingent on low status, as described by Metcalfe et al. $(1989,1990)$. 
TABLE III. Seawater tolerance tests. The percentage of migrant and resident salmon parr that had lost equilibrium at $40 \mathrm{ppt}$ artificial sea water by the three designated time periods

\begin{tabular}{|c|c|c|c|}
\hline & \multicolumn{2}{|c|}{ Removed by } & \multirow{2}{*}{$\begin{array}{l}\text { Remaining } \\
>14 \mathrm{~h}\end{array}$} \\
\hline & $7 \mathrm{~h}$ & $14 \mathrm{~h}$ & \\
\hline Migrants $(n=14)$ & 14 & 14 & 72 \\
\hline Residents $(n=11)$ & 64 & 27 & 9 \\
\hline
\end{tabular}

This possibility is supported by the fact that migrants of the 1989 cohort, which were smaller than the 1988 migrants, also showed little growth over the study period. The low incidence of feeding fish in March is compatible with both explanations, and further work is required with fish housed in size-matched groups to distinguish between the two possibilities.

In earlier work in an artificial stream (Thorpe et al., 1988), salmon parr from the upper modal group did not show more downstream movement than did their lower modal group, non-smolting, siblings. However, the fish in this earlier study were derived from an artificial pairing of adults from the River Almond (Perthshire). Hence, this discrepancy may be the result of a difference in behaviour between stocks, as it is not known if parr from any part of the River Almond migrate downstream in autumn. However, even if they do, the location in the river at which the parent fish used in this earlier experiment might have spawned is not known. It is possible that the fish belonged to a component of the stock from the lower reaches and that, in contrast to the fish from the productively poorer and more exposed high altitude Girnock Burn, there would have been little advantage in migrating downstream in autumn. Riddell \& Leggett (1981) found autumn emigration of parr from the upland, fast-flowing Rocky Brook tributary of the Miramichi River, Canada, while emigration was a strictly spring phenomenon from the lower and slower flowing Sabbies River tributary.

This work was supported by funding from the NERC (grant No. GR9/794) and from the SOAFD Marine Laboratory. We would like to thank Neil Metcalfe, Caroline Askew and Roddy Macdonald for help with screening fish.

\section{References}

Bjornn, T. C. (1971). Trout and salmon movements in two ldaho streams as related to temperature, stream flow, cover and population density. Transactions of the American Fisheries Society 100, 423-438.

Bolger, T. \& Connolly, P. L. (1989). The selection of suitable indices for the measurement and analysis of fish condition. Journal of Fish Biology 34, 171-182.

Buck, R. J. G. \& Hay, D. W. (1984). The relation between stock size and progeny of Atlantic salmon, Salmo salar L., in a Scottish stream. Journal of Fish Biology 24, 1-11.

Calderwood, W. L. (1906). Autumn migration of salmon smolts in Scotland. Reports of the Fisheries Board for Scotland 1905, Part II, 70-74.

Egglishaw, H. J. \& Shackley, P. E. (1973). An experiment on faster growth of salmon Salmo salar (L.) in a Scottish stream. Journal of Fish Biology 5, 197-204. 
Komourdjian, M. P., Saunders, R. L. \& Fenwick, J. C. (1976). Evidence for the role of growth hormone as a part of a 'light-pituitary axis ' in growth and smoltification of Atlantic salmon (Salmo salar). Canadian Journal of Zoology 54, 544-551.

Mason, J. C. (1976). Response of underyearling coho salmon to supplemental feeding in a natural stream. Journal of Wildlife Management 40, 775-788.

Meister, A. L. (1962). Atlantic salmon production in Cove Brook, Maine. Transactions of the American Fisheries Society 91, 208-212.

Metcalfe, N. B. \& Thorpe, J. E. (1992). Anorexia and defended energy levels in overwintering juvenile salmon. Journal of Animal Ecology 61, 175-181.

Metcalfe, N. B., Huntingford, F. A. \& Thorpe, J. E. (1986). Seasonal changes in feeding motivation of juvenile Atlantic salmon (Salmo salar). Canadian Journal of Zoology 64, 2439-2446.

Metcalfe, N. B., Huntingford, F. A. \& Thorpe, J. E. (1988). Feeding intensity, growth rates and the establishment of life history patterns in juvenile Atlantic salmon Salmo salar. Journal of Animal Ecology 57, 463-474.

Metcalfe, N. B., Huntingford, F. A., Graham, W. D. \& Thorpe, J. E. (1989). Early social status and the development of life-history strategies in Atlantic salmon. Proceedings of the Royal Society of London B236, 7-19.

Metcalfe, N. B., Huntingford, F. A., Thorpe, J. E. \& Adams, C. E. (1990). The effects of social status on life-history variation in juvenile salmon. Canadian Journal of Zoology 68, 2630-2636.

Mills, D. H. (1989). Ecology and Management of Atlantic Salmon. London: Chapman \& Hall.

Morrison, B. R. S. (1989). The growth of juvenile Atlantic salmon, Salmo salar L., and brown trout, Salmo trutta L., in a Scottish river system subject to cooling water discharge. Journal of Fish Biology 35, 539-556.

Pyefinch, K. A. \& Mills, D. H. (1963). Observations on the movements of Atlantic salmon (Salmo salar L.) in the River Conon and the River Meig, Ross-shire. I. Freshwater and Salmon Fisheries Research, Scotland 31, 1-24.

Riddell, B. E. \& Leggett, W. C. (1981). Evidence of an adaptive basis for geographic variation in body morphology and time of downstream migration of juvenile Atlantic salmon (Salmo salar). Canadian Journal of Fisheries and Aquatic Sciences 38, 308-320.

Rowe, D. K., Thorpe, J. E. \& Shanks, A. M. (1991). Role of fat stores in the maturation of male Atlantic salmon (Salmo salar) parr. Canadian Journal of Fisheries and Aquatic Sciences 48, 405-413.

Simpson, A. L., Metcalfe, N. B. \& Thorpe, J. E. (1992). A simple non-destructive biometric method for estimating fat levels in Atlantic salmon, Salmo salar L., parr. Aquaculture and Fisheries Management 23, 23-29.

Talbot, C. \& Higgins, P. J. (1983). A radiographic method for feeding studies on fish using metallic iron powder as a marker. Journal of Fish Biology 23, 21 1-220.

Taylor, L. R.\& Taylor, R. A. J.(1977). Aggregation, migration and population mechanics. Nature 265, 415-421.

Thorpe, J. E. (1977). Bimodal distribution of lengths of juvenile Atlantic salmon (Salmo salar L.) under artificial rearing conditions. Journal of Fish Biology 11, 175-184.

Thorpe, J. E., Morgan, R. I. G., Ottaway, E. M.\& Miles, M. S. (1980). Time of divergence of growth groups between potential $1+$ and $2+$ smolts among sibling Atlantic salmon. Journal of Fish Biology 17, 13-21.

Thorpe, J. E., Morgan, R. I. G., Pretswell, D. \& Higgins, P. J. (1988). Movement rhythms in juvenile Atlantic salmon, Salmo salar L. Journal of Fish Biology 33, 931-940.

Wolf, P. (1950). A trap for the capture of fish and other organisms moving downstream. Transactions of the American Fisheries Society 80, 41-45.

Youngson, A. F., Buck, R. J. G., Simpson, T. H. \& Hay, D. W. (1983). The autumn and spring emigrations of juvenile Atlantic salmon, Salmo salar L., from the Girnock Burn, Aberdeenshire, Scotland: environmental release of migration. Journal of Fish Biology 23, 625-639. 